\title{
HISTÓRIA NATURAL E AS IDÉIAS DE GERAÇÃO E HERANÇA NO SÉCULO XVIII: BUFFON E BONNET
}

\author{
NATURAL HISTORY AND EIGHTEENTH-CENTURY \\ IDEAS REGARDING GENERATION AND HEREDITY: \\ $B U F F O N$ AND BONNET
}

Luzia Aurelia Castañeda*

CASTAÑEDA, L. A: 'Natural history and eighteenth-century ideas regarding generation and heredity: Buffon and Bonnet'. História, Ciências, Sauide-Manguinhos, II (2), 33-50 Jul.-Oct. 1995.

The intellectual course of natural bistory reveals three conceptual approaches. The first was the taxonomic point of view, where naturalists worked to name and classify the living beings created by God. The second approach was provided by the eighteenth century's philosophical doctrine of mechanism, which lent natural bistory its method of endeavoring to comprehend the workings of organisms, inasmuch as the world "ran". Calling into question the adequacy of prior message, the third approach argued that living things display characteristics quite distinct from those of non-living matter, making it necessary to understand processes rather than simply decompose phenomena to then analyze them. This inadequacy became apparent at the moment when the ideas of generation and heredity ascribed a reproductive bistory to living things, a bistory where the act of one fellow creature being formed by another plays an important role in coming to understand the workings of life.

The paper analyzes these conceptual approaches from the perspectives of Buffon's and Bonnet's ideas on reproduction and heredity, which represented opposite schools of thought: epigenesis and preformation.

KEYWORDS: natural bistory, bistory of biology, reproduction, beredity, Buffon, Bonnet.

\begin{abstract}
"Dizei que os animais são máquinas, assim como os relógios. Mas colocai uma máquina de cachorro e uma máquina de cadela uma perto da outra, e disto poderá resultar uma terceira máquina, enquanto que dois relógios ficarão um ao lado do outro durante toda a vida sem nunca produzirem um terceiro relógio."
\end{abstract}

Fontenelle

\section{Introdução}

* Centro Simão Mathias de Estudos em História da Ciência da Pontifícia Universidade Católica de São Paulo.
A história natural tratava da história de tudo aquilo que foi 'naturalmente' criado por Deus, então animais, plantas, minerais e homens eram os objetos de descrição e, especificamente no século XVIII, também de classificação dos naturalistas.

As categorias de classificações assim formadas não se relacionavam com as causas da vida, mas, sim, com as suas formas. 
1 Para maiores esclarecimentos entre a forma e a função na história natural, ver Foucault, 1990 , especialmente 'Classificar'.

2 O espermatozóide foi observado pela primeira vez em 1677, por Leeuwenhoek. Em carta enviada ao secretário da Royal Society, Leeuwenhoek descreve a observação de sêmen humano coletado logo após a ejaculação, onde ele pôde notar um grande número de pequenos animalúnculos, menores que um grão de areia, que possuíam corpos arredondados na frente e carregavam uma longa e fina cauda (Farley, 1982, pp. 17-8).
Não era permitido criar, apenas perceber e ordenar. A taxonomia tornou-se o foco das ciências da vida. John Ray (1627-1705) incluiu cerca de 18 mil espécies em sua obra Historia plantarum generalis e foi pioneiro no uso da classificação indutiva, contribuindo para o declínio das divisões dicotômicas; Joseph Pitton de Tounerfort (1656-1708) elaborou categorias mais altas que o gênero (dividiu todas as plantas em 22 classes), criticou o essencialismo predominante desde Aristóteles e buscou caracteres secundários como propagação e aparência; Carolus Linnaeus (1707-78) estabeleceu um prático sistema de classificação baseado em quatro categorias (classe, ordem, gênero e espécie).

Nesse primeiro momento, a história natural não exibia uma relação entre o visível e o invisível, entre a forma e a função. ${ }^{1}$ Por exemplo, a visualização do espermatozóide não lhe conferia a sua função na reprodução, ele era apenas mais um entre os inúmeros vermes encontrados no corpo humano, daí o significado de seu nome: verme do esperma. ${ }^{2}$ Pois se o pensamento que norteava a história natural dos séculos XVII e XVIII era a organização da multiplicidade, o encantamento com a diversidade do mundo criado por Deus, assim quão interessante deveria ser a descrição de mais um verme?

Porém, no percurso intelectual dos naturalistas dessa época, pode-se detectar um processo que vai da percepção do espetáculo da natureza até a busca da compreensão da engrenagem que colocava essa natureza em funcionamento. Ou seja, a conexão entre as diversas formas e as causas e funções que lhes conferiam tais características.

Esse percurso apresenta dois momentos que nos interessam. O primeiro de florescimento da história natural, que, apoiada na filosofia mecanicista, revela seus pressupostos. O segundo momento refere-se ao enfraquecimento da história natural em função da instauração de uma metodologia própria que acusava a inadequação da filosofia mecanicista para a interpretação do fenômeno vida, mais especificamente àquilo que dizia respeito à reprodução, ao mecanismo de produção de semelhantes.

Analisaremos aspectos desse percurso através das idéias de geração e herança de Buffon e Bonnet, representantes das respectivas escolas de pensamento: epigênese e preformismo.

\section{O percurso da história natural}

A história natural experimentou um florescimento no final do século XVII, numa época em que a filosofia mecanicista 
3 A conexão entre razão e natureza vem de uma parte da teologia natural do século XVII inglês. Algumas verdades sobre Deus poderiam ser conhecidas pela observação de sua criação. Tal era a argumentação desse projeto que afirmava que o trabalho de uma inteligência suprema estaria evidente na ordem natural do mundo. triunfava. As principais razões para este entusiasmo teriam sido: os sentimentos anti-religiosos, o desejo de liberação dos princípios anímicos e a ênfase nas ciências empíricas (Hankins, 1985, p. 115).

A filosofia mecanicista aceitava um Deus criador, porém negava-lhe uma intervenção nas operações cotidianas do Universo. Uma vez criada, a obra divina tomaria seu percurso natural. Essa força criadora poderia ser percebida na natureza não por suas ações, mas somente pela extraordinária diversidade e complexidade. Assim, o conhecimento natural coincidia com o conhecimento da criatura. Esse Deus havia emprestado a sua razão às leis da natureza. ${ }^{3}$

Nesse contexto, a razão tornou-se una e idêntica para todo indivíduo pensante. A razão é o ponto de encontro e o centro de expansão do século, a expressão de todos os seus desejos, de todos os seus esforços, de seu querer e de suas realizações (Cassirer, 1992, p. 22).

Quanto ao desejo de liberação dos princípios anímicos, a história natural poderia ser considerada, aqui, talvez, como um complemento à filosofia mecanicista, na qual não haveria lugar para forças espirituais além daquela referente à alma racional humana.

A expansão do conhecimento sobre o mundo natural foi acompanhada por uma reconsideração da natureza da vida, que, apoiando-se em uma filosofia mecanicista, contrapunha-se à visão aristotélica. Assim, quando Harvey, no século XVI, faz sua leitura aristotélica da geração, ele coloca a epigênese como um processo criativo guiado por uma virtude divina. Já a epigênese do século XVIII é um processo divorciado dos princípios anímicos, partindo da homogeneidade da matéria para sua heterogeneidade e complexidade como processo inerente à vida (Westfall, 1977, p. 98).

A ênfase nas ciências empíricas foi mais uma razão para o fortalecimento da história natural. O mundo começa a ser conhecido a partir da observação e do estudo dos fenômenos naturais; não se trata mais de examinar um setor da natureza, mas, sim, de fundamentar a dinâmica, de buscar leis universais.

Para explicar um fenômeno natural não basta apresentá-lo em sua maneira de ser, é necessário fazer ver de que condições particulares tal fenômeno depende (Cassirer, 1992, p. 28). É nesse contexto epistemológico que a história natural se vincula ao paradigma metodológico da física newtoniana: parte-se da observação imediata dos fenômenos, seguida de sua decomposição, para depois efetuar uma síntese que permitirá a generalização. $\mathrm{O}$ animal pode ser explicado como uma máquina, como um 
relógio, onde, decompondo-se suas partes, pode-se entender seu funcionamento geral.

Veremos a seguir como essa formulação da história natural irá perdendo apoio, à medida que as teorias de geração vão acusando a inadequação da filosofia mecanicista para o estudo de seus sistemas. Todavia, enquanto isso não ocorre, o naturalista do século XVIII vai permanecer impregnado dos pressupostos filosóficos de sua época, caracterizando a fase intermediária entre a história natural e as ciências biológicas.

Vejamos o caminho percorrido para se chegar a esse ponto. Desde o ínicio do século XVIII, os filósofos naturais ingleses publicaram uma série de livros que revelavam as maravilhas da criação de Deus através da nova ciência. The sacred cosmology (1701), do microscopista e fisiologista vegetal Nehemiah Grew (1641-1712), que foi seguido por John Ray (1627-1705), em seu livro The wisdom of God manifested in works of the creation (1704). Outros exemplos são Pbilosopbical principles of religion natural and revealed (1705), de George Cheney (1671-1743) William Derham (1657-1735) publicou Pbysico Theology or demonstration of being and atributes of God from bis works of creation (Hankins, 1985, p. 117).

Essas obras evidenciariam o conhecimento do supremo artesão a partir de sua criação, não sendo necessária a Bíblia para provar sua existência. Por exemplo: John Toland (1670-1722) usou o termo panteísmo para definir a crença segundo a qual Deus e a natureza eram uma única coisa. Já Denis Diderot (1713-85), Julien Offray de la Mettrie (1705-51) e o barão D'Halbachi (1723-85) negaram a existência de algum Deus espiritual, insistindo em que a razão e a natureza seriam suficientes (idem, p. 6).

Assim, de forma genérica, os filósofos do Iluminismo envolvidos com as ciências da vida parecem ter aceitado a filosofia mecânica herdada do século XVII. Essa forma de pensar o mundo removia da filosofia natural a idéia de causa final e o conceito aristotélico de forma, substância e acidente que tinham dominado todo o pensamento anterior.

Basicamente, a filosofia mecanicista requeria que o mundo natural fosse explicado somente em termos de movimento e rearranjo de partes da matéria. Mas, para além dessas concepções básicas, os filósofos mecanicistas estavam divididos. Suas teorias concernentes às causas do movimento e à mudança tinham uma imensa variedade de formulações, pois seria a matéria movida por um poder externo, um poder interno ou por nenhum poder? As três posições tiveram argumentos a favor e surgiram posições ideológicas que se prolongaram além do conteúdo filosófico. 
4 Dois autores importantes contribuíram com essa passagem: Diderot, ao contrapor o espírito ordenado e racionalista à apropriação do real em toda sua riqueza, e Buffon, que, ao introduzir um novo método, sugere a multiplicidade das observações precisas, as generalizações e a analogia como auxiliadoras no relacionamento dos fatos.
Nesse ponto do percurso feito pela história natural, era o raciocínio que assegurava a verdade da natureza. Entendendo-se a essência do homem, poderíamos compreender a essência da natureza. Temos, nesse momento, a fisiologia humana como ponto de partida que revelaria a chave do conhecimento do mundo e começa, então, a ser esboçado o fim do monopólio da matemática em detrimento da experimentação e da observação. "Assim o fundamento da física deixa de residir na análise das sensações para localizar-se na história natural, na fisiologia, na medicina" (Cassirer, 1992, p. 100).

É nessa transição que o método próprio da história natural começa a surgir. Contrapondo-se à física, na qual a descrição exata dos fenômenos coincide com suas medidas e inter-relações, as ciências da vida, ao descreverem os fenômenos, tinham que conservar a forma própria e específica de seu objeto. Ele deveria ser exposto em toda sua riqueza e diversidade. ${ }^{4}$

Esse novo método das ciências naturais transfere o foco das leis matemáticas para o conhecimento do processo, no qual o ser vivo tem uma história reprodutiva, perpetuada por algum mecanismo ainda desconhecido e onde, também, o indivíduo passa a receber mais atenção que o gênero. $O$ mecanicismo deixa de ser considerado o princípio único e suficiente de toda explicação (idem, p. 117).

Chegamos ao ponto crítico, que abala o casamento entre a história natural e o mecanicismo. As plantas e os animais não podem ser reduzidos ao mundo mecânico, pois a vida se expressa de modo universal. A formação do semelhante pelo semelhante confere àquilo que é vivo um tratamento diferenciado do bruto, do inanimado. Por que um animal produz outro animalzinho e um relógio nunca produzirá outro relogiozinho, se ambos funcionam como uma máquina? É a reprodução que dá ao vivo um status distinto, onde a filosofia mecanicista, pela primeira vez, se apresenta inadequada, porém ela não é totalmente excluída do pensamento biológico nascente. A matéria viva, dotada de poder de criação, é interpretada por alguns naturalistas do século XVIII como possuidora de memória e dinamismo. É uma matéria que manifesta repulsão, atração e mobilidade, atribuindo ao mundo vivo a diversidade tão sedutora aos olhos iluministas.

São essas qualidades da matéria viva que, por um lado, libertaram a criatura do criador, mas, por outro, impregnaram o mundo vivo de uma concepção mecânica de funcionamento. É nesse âmbito transitório entre deuses e máquinas que as idéias de geração e herança puderam ser pensadas. 


\section{Geração e herança}

Como vimos até agora, para decifrar a natureza e descobrir suas leis não bastava mais pesquisar e agrupar as identidades e as diferenças entre as coisas e os seres, a fim de classificá-los. Era preciso que os dados empíricos se articulassem em profundidade, vislumbrando, assim, a função das coisas até então observadas e categorizadas. Seria, pois, a vida a referência que permitiria ligar as representações e estabelecer as relações não somente entre os diferentes seres, mas entre os diferentes elementos de um mesmo ser. Seria, assim, o conceito de vida, no estudo do mundo vivo, que permitiria alcançar e realizar uma síntese entre forma e função.

Esse conceito, que está se formando em meados do século XVIII, traz em sua essência a idéia de reprodução, a formação do novo ser. A questão a ser abordada é, então, como ocorre esse processo que tem permitido à obra divina fecundar e povoar o mundo. Existem dois aspectos que interagem e se confundem: onde está o embrião e como ele se desenvolve?

Duas descobertas importantes permearam as discussões nessa época: $a$. após inúmeras dissecações, verificaram-se, nos "testículos" (ovários) de fêmeas vivíparas, pequenas massas repletas de um líquido semelhante à clara do ovo e que se tornava amarelo depois da cópula. Essa pequena massa passou a ser relacionada aos ovos. Portanto, desde finais do século XVII, começou-se a considerar que todas as fêmeas possuíam ovos (Jacob, 1983, p. 62); b. quanto à semente masculina, o microscópio já havia revelado que no sêmen existiam pequenos "vermes" que, de alguma forma, poderiam estar relacionados com a reprodução.

A essas descobertas seguiu-se a formação de duas escolas de pensamento: a epigênese e o preformismo.

Os epigenesistas acreditavam na geração de um novo indivíduo a partir da mistura de sementes masculinas e femininas e que de uma matéria homogênea iriam se desenvolvendo as múltiplas formas.

A epigênese do século XVIII sustentava que alguma força físico-química deveria influenciar a geração; por exemplo, Maupertuis sugeriu forças que se assemelhavam à atração existente em reações químicas, enquanto Needham acreditava em uma força gerativa e Buffon especulava sobre moléculas orgânicas que tomariam formas em um molde interior, ao qual atribuía forças gravitacionais (Carozzi, 1985, p. 226).

Assim a epigênese de cunho mecanicista do século XVIII abandonou a idéia aristotélica, segundo a qual as substâncias amorfas tomavam uma forma em potência, mas não em ato. Passando, 
5 A idéia de que o sangue menstrual seria o equivalente ao sêmen masculino pode ser encontrada desde Aristóteles. Este acreditava que o fluxo mensal (catamenia) relacionava-se com a geração do novo ser, porém sua contribuição era distinta do sêmen masculino. Enquanto a fêmea contribuía com a matéria, através de seu fluxo mensal, a semente masculina conferia forma e movimento a essa matéria. assim, a atribuir à geração uma causa imediata e mecânica de interação de forças naturais.

Por sua vez, a teoria do preformismo aceitava que o embrião já existente nunca era produzido pelos pais, mas foi criado por Deus no início dos tempos e permaneceu neste estado até o momento de seu desenvolvimento.

Essa era a concepção básica dos preformistas, porém eles divergiam quanto à localização do germe preformado. Havia aqueles que acreditavam que o espermatozóide continha dentro de si um embrião, um pequenino ser, que era capaz de se desenvolver durante a gestação. Os opositores dessa visão acreditavam que o embrião se encontrava no ovo, necessitando somente do estímulo do sêmen para crescer e se desenvolver. Dessa forma, a contribuição material da fêmea para a prole não seria meramente o líquido menstrual, mas, sim, uma complicada estrutura sólida (Zirkle, 1946, p. 139). ${ }^{5}$

O interesse pela reprodução e desenvolvimento dos seres vivos, principalmente aqueles que eram úteis aos homens, é anterior ao esclarecimento de como esses fenômenos ocorrem, ou mesmo à reflexão sobre tais acontecimentos, ou seja, as observações empíricas pré-datam a ciência e a filosofia. Por exemplo, os cientistas não apreciaram a sexualidade das plantas até o trabalho de Camararius (1665-1721), embora a polinização cruzada de palmeiras já houvesse sido efetuada por muitos séculos. Parece que, nesse momento da história natural, a observação não se limitava à constatação da diversidade ou até à sua manipulação por intermédio de cruzamentos dirigidos, mas o espírito do naturalista de meados do século XVIII quer se infiltrar nas formas para tentar capturar o processo vital, quer entender a história reprodutiva.

Parecia ao mesmo tempo estranho e maravilhoso que a prole fosse sempre similar, mas nunca idêntica aos pais. Por quais motivos seriam eles semelhantes ou diferentes? O que causaria os desvios de uma forma normal ou mesmo a formação de monstros? Em que os dois sexos contribuiriam para a formação do novo ser? O que faria que um organismo se desenvolvesse? Como era possível para algumas formas se regenerarem, enquanto outras permaneciam mutiladas? Enfim, olhando para a história da geração, podemos perceber, mais claramente do que em qualquer outro campo da biologia, os problemas filosóficos e científicos concernentes à questão vida.

De Hipócrates até o presente, os estudiosos olharam para as mesmas estruturas, porém de formas e em condições diferentes, o que conseqüentemente levou a conclusões também diferentes. 
6 A primeira edição desta obra é de 1762 , porém a edição aqui referida se baseia na versão publicada por Bonnet em $1778 \mathrm{e}$ que contém muitas notas adicionais.

7 Minúsculas sementes que continham o embrião preformado ou parte dele, por exemplo, germes do braço continham outros braços menores ainda e assim por diante.

\footnotetext{
8 Todas as traduções foram feitas pela autora.
}

Vejamos, a seguir, de forma mais específica, através de dois estudiosos do século XVIII, como puderam ocorrer diferentes teorias acerca da reprodução e herança, embora impregnadas do mesmo substrato filosófico.

\section{Charles Bonnet (1720-93)}

Charles Bonnet, em sua obra Considérations sur les corps organisés, ${ }^{6}$ apresenta como tema principal a discussão entre o preformismo e a epigênese. Ele era um preformista convicto e opôs-se às teorias atomistas de geração propostas por Buffon, Needham e Maupertuis, que tentaram explicar a embriogênese pela justaposição de partes derivadas de fluidos seminais provenientes de ambos os sexos, um processo governado por leis do movimento e por propriedades inerentes à matéria.

Contrária a essa última perspectiva, que poderíamos definir como materialista, a preformação permitiu traçar uma cadeia de causalidades que levaria à formação de um embrião voltado ao Criador e, tendo neste sua causa primeira, razão suficiente, portanto, para a organização da matéria (Rieppel, 1985, p. 359).

Durante décadas, Bonnet hesitou entre a doutrina do embôेtement, que implicava a encapsulação de germes ${ }^{7}$ uns dentro de outros e a doutrina da dissimilação, ou seja, a dispersão universal de diminutos e invisíveis germes.

Assim, na problemática do preformismo, além do questionamento sobre qual seria o lugar do germe (se no ovo ou no espermatozóide), surge também um outro debate, delineado por duas vertentes: uma que supõe a existência de germes espalhados por toda parte e de todos os tipos, que se desenvolvem quando encontram o local adequado; e outra, que supõe os germes como já estando 'encaixados' uns nos outros, em uma sucessão indefinida de gerações. Como veremos a seguir, Bonnet (1985, p. 87) não se posiciona definitivamente em nenhuma delas, mas prefere a concepção do encaixamento:

"Já me expliquei: não tomarei um partido entre a hipótese que espalha os germes por toda parte e a que os encaixa uns dentro dos outros. Essas duas hipóteses possuem, cada uma, sua probabilidade: mas não se deve supor um encaixamento ao infinito, o que seria absurdo. A divisibilidade da matéria ao infinito, pela qual se pretendeu manter esse encaixamento, é uma verdade geométrica e um erro físico. Todo corpo é necessariamente finito; todas as suas partes são necessariamente determinadas: mas essa determinação nos é desconhecida."8 
Por outro lado, Malebranche (1638-1715) tinha apoiado a doutrina do encaixamento em sua obra De la recherche de la varieté. Os experimentos de Reámur (1683-1767), sobre a regeneração de crustáceos, apontavam para a mesma direção, assim como o próprio trabalho de Bonnet sobre a regeneração de membros acrescentou uma maior plausibilidade a essa teoria (Rieppel, 1985, p. 360).

Assim, para explicar o que ocorre quando uma planta ou um animal se reconstitui ou se reproduz por brotamento, Bonnet (1985, pp. 39-40) vai supor que o corpo todo do indivíduo contém um grande número de germes que se desenvolvem em condições adequadas:

"...vê-se que esses vermes se multiplicam por cortes, como as plantas. Tudo ocorre pelo desenvolvimento de partes preexistentes. Nenhum mecanismo conhecido por nós é capaz de formar um coração, um cérebro, um estômago etc. Os germes espalhados por todo o corpo desses animais apenas aguardam uma circunstância favorável para se desenvolverem. O corte produz essa circunstância. Ele desvia, em benefício dos germes, a parte do fluido alimentar que teria sido empregada para o crescimento do verme inteiro; da mesma maneira que, quando podamos uma árvore, ou fazemos cortes em um de seus ramos grossos, vê-se saírem, em torno do corte, um grande número de botões que, sem essa operação, não teriam sido desenvolvidos."

Essa explicação apresenta algumas dificuldades, pois, sendo o germe um tipo de miniatura de todas as partes do corpo, por que apenas algumas partes poderiam desenvolver-se sem que as demais também o fizessem? Bonnet considera duas possibilidades: ou a pressão das partes próximas impede o crescimento de outras partes do germe, ou, então, existem germes parciais de cada órgão.

A segunda possibilidade, que parece ser a mais plausivel para Bonnet, é a de que a reprodução de cada membro será realizada por um germe apropriado. Em sua primeira aparição, o membro é de um tamanho muito pequeno e, no entanto, já contém todas as formas, de modo reduzido, que o membro apresentará ao longo de seu desenvolvimento.

Bonnet discute a localização da alma e o que ocorre quando, pelo corte de um único animal, obtêm-se dois ou mais animais. Por fim, ele conclui que apenas a parte onde ficou o cérebro é que mantém a alma antiga e que somente surgirá uma nova alma quando outro cérebro for formado.

Portanto, se para Bonnet o germe é um animal em miniatura, qual seria então a diferença para o animal desenvolvido? Ele 
responde a isso afirmando que o primeiro é composto apenas pelas partículas elementares e que as malhas que elas formam são tão estreitas quanto possível, enquanto que no segundo, ou seja, no animal desenvolvido, as partículas elementares se uniram a outras partículas fornecidas pela nutrição.

Para compreendermos melhor essa diferença, é necessário entendermos como ocorre o desenvolvimento para Bonnet. Segundo este, o desenvolvimento, a partir do embrião ou da semente, é um simples crescimento do germe preexistente. Ainda segundo Bonnet, pode-se observar, em pequena escala, as mesmas partes essenciais que o animal terá em maior escala. Portanto, a geração nada mais é do que o desenvolvimento de germes adequadamente nutridos.

Para Bonnet, os canais de circulação por onde passarão os líquidos nutritivos, como também os outros órgãos, serão formados por elementos particulares e será a natureza, a forma e o arranjo desses elementos que determinarão a espécie do corpo organizado.

O corpo todo se desenvolve pelo aumento das fibras simples que recebem o alimento. Os elementos das fibras são como um substrato que recebe as partículas do fluido nutricional, as quais, por sua vez, se reúnem por afinidade. Assim as fibras constituiriam um tipo de estrutura em rede.

Quanto ao líquido seminal, Bonnet (idem, p. 30) supunha que este conteria os elementos de todas as partes do corpo organizado, como um tipo de extrato do corpo capaz de nutrir o germe nos seus primeiros estágios de desenvolvimento. Esse extrato, composto por sucos nutritivos, abriria as malhas sólidas do germe, iniciando os primeiros movimentos internos.

Outro ponto obscuro, para Bonnet (ibidem, pp. 36-7), estaria na questão do princípio da circulação no germe. Para ele, não ocorreria nenhuma circulação no germe não fecundado, tudo permanecendo em repouso perfeito, mas, durante a fecundação, o líquido seminal seria levado aos órgãos de circulação do germe e os dilataria, sendo esta dilatação naturalmente seguida pela reação do canal sobre o líquido e a circulação começaria aí a se realizar. O líquido seminal, levado por esse caminho a todas as partes, abriria as malhas das fibras simples e as colocaria em condições de receber os sucos que o útero lhe estava enviando.

Com isso, o líquido seminal apresenta um poder de modificação do germe, podendo, portanto, imprimir nele traços semelhantes ao pai (p. 426). É dessa forma que Bonnet tenta explicar por que os filhos podem ter características parecidas com as do pai.

Este será, pois, o ponto mais delicado da proposta de Bonnet, pois, se ele acredita que o animal já existe dentro da fêmea, 
antes da fecundação, como, então, o germe poderá ser alterado pelo macho e receber características deste?

Bonnet responderá que o líquido seminal tende a abrir e a desdobrar os órgãos do germe, sendo que a sua ação depende do maior ou menor número de moléculas de cada gênero, estimulando o crescimento de alguns órgãos e impedindo o de outros: "se há mais moléculas apropriadas a um certo órgão, ou se essas moléculas são mais ativas, esse órgão se desenvolverá mais. Ele receberá por sua impressão outras modificações particulares, em conseqüência de uma disposição que lhe dá mais ou menos consistência, deixando-o membranoso ou determinando a sua ossificação" (pp. 428-9).

Além das impressões gerais deixadas pelo líquido seminal, este também servirá como um estimulante vital, irritando o coração do germe:

"O esperma penetra, portanto, no germe e sua influência não se limita a animar o coração. $O$ cavalo desenhado em miniatura no ovário da égua recebe da impressão do esperma um órgão que não tinha originariamente. O líquido do burro parece, portanto, transformá-lo em mula. ... A parte mais sutil de um líquido tão elaborado parece apropriada para se insinuar nos vasos infinitamente delicados do germe. Os fatos provam que ele o penetra. Ele também poderia aí circular e produzir, por sua ação imediata sobre diferentes partes, esses traços de semelhanças, dos quais procuramos descobrir as causas" (pp. 412-3).

Apesar de influenciar o germe, Bonnet (p. 415) acredita que o sêmen não pode transmitir um novo órgão, pois ele não forma nada, apenas modifica aquilo que já estava preformado. Os diversos traços de semelhança que a fecundação imprime ao germe não poderiam representar com fidelidade o original. Não seriam, assim, propriamente cópias, não tomariam sua impressão como um molde. Ou seja, em nossa linguagem, diríamos que os processos de herança paterna e materna são diferentes e que o pai só pode 'alterar' aquilo que já existe, mas a estrutura é dada pela mãe. Bonnet tenta esclarecer da seguinte maneira: se cruzarmos um touro, que tem quatro estômagos, com uma fêmea de burro, que tem somente um, provavelmente o híbrido terá apenas um estômago que, possivelmente, sofrerá grandes mudanças por influência do sêmen. Tais mudanças podem chegar ao ponto de fazer com que o estômago do híbrido pareça dividido ou multiplicado.

Bonnet (p. 423) acreditava que só a parte líquida do sêmen masculino possuía efeitos fecundantes e baseou essa sua crença nos experimentos de fecundação artificial realizados por Spallanzani. 
Os fenômenos da hereditariedade e das malformações, dentro do contexto preformista, traziam consigo a idéia de que os monstros tinham sido criados por Deus, idéia essa que Bonnet rejeitava. A solução encontrada por ele foi a de restringir a preformação a características essenciais da espécie, explicando os problemas da variação individual hereditária como sendo o resultado de influências externas e acidentais sobre o embrião durante o processo de seu crescimento e evolução.

Como vimos, Bonnet visualizou o germe como constituído de fibras elementares. Partículas nutritivas que vinham de fora poderiam ser assimiladas nas próprias malhas das fibras pela ação das forças atrativas. E, assim, postulou que o fluido seminal constituiria o primeiro material nutritivo do germe. Esta hipótese ajudou-o a explicar o dimorfismo sexual e a herança de características paternas nos híbridos dentro de um contexto ovista. Porém, para a herança materna, Bonnet forneceu argumentos que podem ser considerados não muito fortes. Por exemplo, ele admitia que, do mesmo modo como os órgãos de reprodução masculinos podiam capturar moléculas que determinariam as características do pai, os órgãos de reprodução femininos poderiam capturar do sangue da mãe moléculas que determinassem as características maternas (Rieppel, 1985, p. 362).

Com essa hipótese, Bonnet acreditava ter resolvido o problema da hereditariedade e da variação individual. Porém, na verdade, dessa forma ele acabou por se aproximar da lógica atomista, segundo a qual os fetos formavam-se pela justaposição de partículas derivadas dos fluidos seminais femininos e masculinos, que, por sua vez, derivam da superabundância do material nutritivo no sangue.

Argumentando que a estrutura do corpo do pai controlaria a natureza do material que suplementa o germe, Bonnet era capaz de explicar como peculiaridades individuais poderiam ser passadas de uma geração a outra. Ele poderia, assim, aceitar a produção de novas variedades dentro da espécie, mas sempre deixando claro que a estrutura da espécie permaneceu e permanecerá absolutamente a mesma, pois o germe carregaria a marca original das espécies e não do indivíduo. Teríamos, pois, um homem, um cavalo, um boi etc. em miniatura, mas não um certo homem, um certo cavalo, um certo boi (Bowler, 1973, p. 263).

\section{George-Louis Leclerc de Buffon (1707-88)}

Buffon acreditava que a matéria no universo era de dois tipos fundamentais, o orgânico e o inorgânico. Essa matéria era feita de 
partículas primárias vitais, idênticas e indestrutíveis. Esses átomos tinham tendência a se unirem para formar grupos com um padrão definido. Justamente como o grão de sal era feito de numerosos grãos menores, os organismos eram compostos de numerosas réplicas diminutas, sendo cada unidade um grupo de partículas primárias.

O crescimento poderia ser explicado assumindo-se que as partículas orgânicas vitais, liberadas de outros corpos depois da morte, ficariam no solo e no ar e seriam eventualmente absorvidas pelas plantas. Dentro destas, as partículas vitais reformulavam-se em novos grupos, como aqueles que já estavam lá e, então, as plantas cresceriam. Assim, uma certa quantidade de matéria orgânica estaria sempre presente nas plantas e nos animais. O alimento era quebrado em seus constituintes e as moléculas orgânicas essenciais eram absorvidas dentro do organismo, onde se reuniriam com unidades já presentes (Gasting, 1967, p. 87).

Buffon percebe que existe algo como que oculto na formação do semelhante pelo semelhante. A partir dessa percepção passa a relacionar as estruturas visiveis e externas com estruturas invisíveis, onde a abstração e a analogia são empregadas como métodos de análise.

Por meio de analogias, Buffon tenta separar os organismos, observando as propriedades comuns e as diferenças. Assim, considera os minerais como matéria bruta, inativa, insensivel, sem organização, desprovida de todas as faculdades, mesmo a de se reproduzir, enquanto que, para ele, o animal reuniria todos os poderes da natureza. Conseqüentemente, Buffon irá agrupar numa mesma ordem os animais e os vegetais, sendo a reprodução a característica comum a ambos, através da qual produzem seus semelhantes e perpetuam a espécie.

Dedicando o segundo capítulo de sua obra Histoire générale des animaux à discussão da reprodução em geral, Buffon atribui a esse termo uma conotação mais ampla do que aquela existente em sua época, passando a significar não só reformação de partes do corpo como também a geração de outros organismos. Tentando explicar esse fenômeno, Buffon diz que na natureza existe uma matéria orgânica, comum a todos os seres, tanto animais como vegetais, que serve à sua nutrição, ao seu desenvolvimento e à sua reprodução. Essa matéria seria composta de parcelas indestrutíveis e incorruptíveis, às quais ele chama de moléculas orgânicas (Buffon, 1853, pp. 437-8).

Utilizando-se de uma analogia com a arte, Buffon (idem, p. 443) argumentaria que, da mesma forma como na pintura e na escultura têm-se representações de superfícies externas, pode existir algum 
mecanismo interno no qual se processe a "reprodução", o "molde interior".

Tanto a reprodução como a regeneração e o crescimento estariam, para Buffon, relacionados com a existência desse molde interior, onde as moléculas orgânicas se agrupariam por afinidade, da mesma forma que o fenômeno da queda livre e dos movimentos planetários justificavam a hipótese da gravidade universal. Impressionado com a física newtoniana, Buffon sugeriu que o molde interior provavelmente possuiria uma força atrativa. As moléculas seriam introduzidas no corpo pela alimentação e só operariam no desenvolvimento do organismo quando incorporadas intimamente às partes que lhes correspondessem. Essa incorporação íntima ocorreria através do molde interior. Esse termo é ambíguo e seu significado foi muito discutido. Maupertuis, e depois Cuvier, se queixaram de nunca o terem compreendido muito bem, pois poderia se referir tanto ao mecanismo pelo qual as moléculas vão se distribuir no organismo, através das semelhanças entre si, como também ao próprio corpo possuidor de uma forma oca onde as moléculas se agrupariam, ou, ainda, a um processo onde essas duas interpretações ocorreriam simultaneamente.

É nesse contexto hipotético que Buffon (p. 456) especula sobre a natureza do sêmen, que seria um tipo de extrato formado por moléculas supérfluas. Buffon considerava que o desenvolvimento e o crescimento das diferentes partes do corpo se faziam pelo preenchimento do molde interno. Quando um organismo chegasse ao final de seu crescimento ele não precisaria mais de grandes quantidades de moléculas orgânicas, que se tornariam, então, supérfluas, o que corresponderia, para Buffon, à puberdade. Essas moléculas que estariam sobrando seriam moldadas pela parte que lhe corresponde, levando, portanto, uma impressão daquela parte, só então seriam enviadas aos reservatórios seminais, onde iriam constituir os licores seminais. Portanto, dentro do licor seminal, masculino e feminino, são encontrados todos os tipos de moléculas presentes no corpo daquele indivíduo.

Buffon (p. 461) percebe que nos organismos que se reproduzem assexuadamente as moléculas orgânicas conseguem se reunir para formar pequenos seres organizados; já naqueles em que a reprodução se faz pela união de licores seminais masculinos e femininos, as moléculas orgânicas desses licores, quando isoladas, não conseguem se agrupar de modo organizado. Ele não esclarece, todavia, o porquê da necessidade de mistura para a formação do novo ser. Apenas argumenta que a prova de que há mistura de licores 
seminais é que um filho pode apresentar tanto características do pai como da mãe:

"Mas uma prova muito mais forte que todas as outras explicações é a semelhança dos filhos com seus pais: os filhos se assemelham, em geral, mais ao pai do que à mãe, e a filha mais à mãe do que ao pai, isso porque um homem se parece mais com um homem do que com uma mulher, e uma mulher se parece mais com uma mulher do que com um homem na forma geral dos corpos, mas, para feições e características particulares, as crianças se parecem tanto com o pai quanto com a mãe, ou mesmo com os dois, por exemplo, os olhos do pai e a boca da mãe, ou a cor da mãe e a estatura do pai, isso só é possível de conceber, a menos que se admita que os dois pais contribuam na formação do corpo do filho, e que por conseqüência haja uma mistura de licores seminais."

Ainda de acordo com Buffon (p. 456), a formação do feto se operaria após a mistura dos sêmens dentro do útero da mãe. As moléculas dos órgãos sexuais, que são diferentes em cada semente parental, serviriam de apoio, de centro de reunião às demais moléculas, que, por agregação das semelhantes, iriam formando os diferentes órgãos.

Uma criança se parecerá mais com o pai ou com a mãe dependendo da quantidade de moléculas organizadas que vierem dos progenitores. Ou seja, se um feto for macho, seus órgãos sexuais serão compostos somente por moléculas provenientes dos órgãos sexuais do pai. Porém, todo o restante do corpo será constituído de moléculas paternas e maternas. O que determinará quais moléculas entrarão em maior quantidade na formação do novo ser é a proximidade a que essas moléculas estarão do ponto de apoio ou do centro de reunião dado pelas moléculas dos órgãos sexuais. Então, se as moléculas maternas, responsáveis pela formação do nariz, estiverem mais próximas do centro de reunião do que as paternas, o novo indivíduo terá um nariz parecido com o da mãe e assim por diante: "...as moléculas só podem se reunir quando os dois licores seminais dos dois sexos se misturaram, e quando dentro da mistura se encontram mais moléculas orgânicas do macho do que da fêmea, o resultado é um macho, ou ao contrário, se há mais partículas orgânicas da fêmea do que do macho, se formará uma fêmea".

Buffon chega a afirmar que há mais formação de homens do que de mulheres porque essas são, em geral, mais delicadas e menores do que os homens, tendo, portanto, menor quantidade de moléculas supérfluas e conseqüentemente seus licores seriam menos abundantes. 


\section{Conclusão}

O objetivo do naturalista do século XVIII era encontrar um sistema que identificasse as plantas e os animais por meio de sua essência - a alma racional, que se expressava no nível visível, evidenciando o plano traçado por Deus.

Através da observação, a descrição traduzia em palavras o que era visto: a nomeação do visível que decompõe o todo e detalha seus elementos. A história natural seria uma ciência taxonômica, classificatória.

A partir da idéia ou do conceito de espécie, no qual existe uma ordem articulando as essências visíveis, surge uma necessidade de fundar as classificações na realidade da natureza, ou seja, na recorrência a um elemento exterior não baseado unicamente na estrutura visível, mas na permanência desta estrutura através de gerações. Instaura-se, assim, a possibilidade de um pensamento voltado para as questões da hereditariedade que garante a permanecência das formas vivas desde a criação. Isso não significou que essa possibilidade pudesse se concretizar de imediato. Mas, em alguns naturalistas, principalmente entre os adeptos da epigênese, as idéias de hereditariedade irão permear suas teorias.

Tendo como suporte filosófico o mecanicismo e como suporte conceitual a epigênese e o preformismo, tanto Buffon como Bonnet caracterizaram a matéria viva como um poder de reprodução, conferindo àquilo que é vivo um status diferente da matéria bruta.

Quanto ao conceitual reprodutivo, esse poder se expressa de formas distintas entre esses dois autores, porém em ambos a matéria viva apresenta um dinamismo, seja na reunião das moléculas orgânicas, seja na influência do líquido seminal nos interstícios do germe preformado ou mesmo na regeneração.

Quanto à qualidade de memória dessa matéria viva, podemos observar diferenças nos dois autores. Buffon, com suas moléculas orgânicas e seu molde interior, consegue conceituar tal qualidade. A matéria viva, para Buffon, consegue não só deixar traços, como também criar novas formas, dependendo da quantidade e da distribuição em que as moléculas orgânicas se encontram dentro do molde interior do novo ser. Enquanto que, para Bonnet, existe apenas uma vaga capacidade de deixar impressões, pequenas modificações causadas pelo líquido seminal ao abrir os canais em repouso do germe já existente. Nesse contexto, a influência materna é dificilmente explicada. Como a prole pode se parecer com a mãe, se esta não emite nenhum sêmen, apenas 
carrega dentro de si aquilo que já foi criado desde o ínicio dos tempos?

Outro aspecto importante para nossa análise é a característica deísta da maioria dos filósofos do século XVIII: Deus não interferia no Universo depois de criado. Assim, para Buffon, as moléculas orgânicas não são instrumentos divinos; para cada concepção, são atribuídas causas imediatas e mecânicas de forças naturais. Enquanto que, para Bonnet, o embrião nunca é realmente formado pelos pais a partir de causas atuais, mas criado por Deus, o qual, portanto, ainda está presente no cotidiano da concepção. A preformação de Bonnet não consegue explicar a malformação e o surgimento de monstros, pois esses não seriam obras do divino. As variações individuais eram decorrentes de influências externas e acidentais.

Foi, portanto, entre deuses e máquinas que as idéias de herança puderam ser pensadas. Para Buffon, a possibilidade de explicação da semelhança contribuiu com a fundamentação de suas idéias de reprodução. Já para Bonnet, ao contrário, a fragilidade de seus argumentos sobre a formação de semelhantes, imposta por seu conceitual preformista, vem enfraquecer seu ponto de vista.

Assim, a história natural, quando tocada pelas idéias de herança, começa a contar uma outra história: a biologia.

CASTAÑEDA, L. A.: 'História natural e as idéias de geração e herança no século XVIII: Buffon e Bonnet'. História, Ciências, Saúde - Manguinbos, II (2) 33-50 jul.-out. 1995.

No percurso intelectual da história natural pode-se detectar três aspectos conceituais.

O primeiro deles é dado pelo enfoque à taxonomia, na qual o naturalista tinha como objetivo nomear e classificar os seres criados por Deus. O segundo aspecto é dado pelo suporte filosófico da época.

O mecanicismo, emprestando seu método de análise à história natural, buscou compreender a engrenagem dos organismos, pois o mundo 'funcionava'. O terceiro aspecto aponta para uma inadequação do méto- do até então utilizado, pois, diante de uma matéria viva que apresentava características distintas da ma- téria bruta, havia a necessidade de se entender o processo e não apenas decompor os fenômenos para, então, analisá-los. É nesse ponto do percurso que as idéias de geração e herança evidenciam tal inade- quação, atribuindo ao ser vivo uma história reprodutiva, na qual a formação do semelhante pelo seme- lhante tem um papel importante para a compreensão da engrenagem da vida.

O presente artigo apresentará uma análise desses aspectos, fundamentada nas idéias de reprodução e herança de Buffon e Bonnet, representantes de escolas distintas de pensamentos: a epigênese e o preformismo, respectivamente.

PALAVRAS-CHAVE: história natural, história da biologia, reprodução, herança, Buffon, Bonnet.

\section{REFERÊNCIAS BIBLIOGRÁFICAS}

Bonnet, $\mathrm{C}$. 
Bowler, P. J. 1973

Buffon,

G. L. L Conde de 1853

Carozzi, $M$. 1985

Cassirer, E. 1992

Farley, J. 1982

Foucault, M. 1990

Gasting, E. B. 1967

Hankins, T. L. 1985

Jacob, F. 1983

Rieppel, O. 1985

Westfall, R. 1977

Zirkle, C. 1946
'Bonnet and Buffon: Theories of generation and the problem of species. Joumal of the History of Biology, 6: 250-8.

'Histoire générale des animaux', vol. 1.

Em Oeuvres complètes de Buffon et la classification de Cuvier. Paris, Garnier, 12 vols.

'Bonnet, Spallanzani, and Voltaire on regeneration of heads in snails: A continuation of the spontaneous generation debate'. Gesnerus, 42: 265-88.

A filosofia do Iluminismo.

Campinas, Editora da Unicamp.

Gametes \& Spores: Ideas about sexual Reproduction 1750-1914.

Londres, The Johns Hopkins University Press.

As palavras e as coisas: uma arqueologia das ciências bumanas. São Paulo, Martins Fontes.

Investigation into generation: 1651-1828. Londres, Hutchinson \& CO.

Science and Enlightenment.

Londres, Cambridge University Press.

A lógica da vida: uma bistória da bereditariedade. Rio de Janeiro, Graal.

'The dream of Charles Bonnet (1720-1783)'. Gesnerus, 42: 359-67.

The construction of Modern Science: Mechanisms and Mechanics. Londres, Cambridge University Press.

'The early history of ideia of inheritance of acquired characteres and Pangenesis'. Transaction of the American Pbilosopbical Society, 35: 91-151.

Recebido para publicação em abril de 1995. 